\title{
Crucial Teaching Strategies for Engineering Educators
}

\author{
Dr. John A. Marshall, Dr. June E. Marshall \\ University of Southern Maine / Saint Joseph's College
}

The purpose of this paper is to identify and describe teaching tools and techniques that will help new faculty as well as experienced faculty become more effective teachers. Based on a review of the literature, the following excerpts have been divided into two major sections. The focus of the first section is the learning process, and the second section discusses innovative methods of teaching.

Topics included in the "Learning" section include: 1) Focusing on Learning and Not Teaching; 2) Problem Based Learning; 3) Facilitating Group Learning (Promoting Accountability, Linking Assignments, and Stimulating the Idea Exchange); 4) Changing Learning Behavior Outside the Classroom; and 5) Preparing to Teach. Topics included in the "Teaching" section include: 1) The Seven "Good Practices" for Teachers; 2)

Teaching with Hospitality; 3) The Importance of Listening; and 4) Assessment Via the Minute Paper.

The presented techniques are not cumbersome or extremely involved. In fact they are fun and very straightforward. Learn more about these practical and helpful teaching ideas that can easily be implemented into your curriculum. Examples and brief case studies are utilized to increase clarity and understanding.

\section{Learning Technique Number 1 - Focusing on Learning and Not Teaching}

Spence's (2000) article, Maybe Teaching is a Bad Idea, suggests that educators should be more focused on the learning process rather than strictly on the teaching process. Too often we follow a primitive but intuitive teaching model such as: "You go to school, a smart person tells you something, and you are expected to learn it and remember it, and if you don't, you are stupid."

According to this model, teaching is telling, and learning is bulimic. Some 70 years of research shows that telling, in the form of lecturing, is just as good for transmitting information as, but no better than, reading a book, listening to a tape, or watching a film. The same research shows that within weeks and months, students retain only 10 percent of that information. Even then, they can rarely apply it to the messy problems of business and life. 
Why, of all the human arts, does college teaching not improve? From Plato's academy of the fifth century B.C. to the research university of today, professors have taught much the same way, with indifferent results. A few students learn very well, many learn a little, and a few nothing at all.

What is a better idea? Try learning. Learning is something students do. It requires compelling problems and well-designed laboratories, studios, workshops, and playing spaces. It demands strenuous efforts and experts to intercede with stories, admonitions, or principles when students fail, as they must, if they are to learn. Most of the learning that results in the expertise of the practicing scientist, engineer, or poet is accomplished through hands and minds on a task. Just think of the contrast between the activities of apprentices in a workshop and the passivity of pupils in a lecture hall.

If we refocus our efforts on learning, professors can exploit information technology to provide data, scholarly references, and simulated problems for cognitive workshops. In those workspaces, student investigators will work side by side with faculty. Together they will learn to create, evaluate, improve, and apply knowledge. Students will learn to be experts and faculty will sharpen their expertise.

There won't be "a" talking head, but scads of conversations. There will be students tearing into problems with all the vitality of youth. And there will be, liberated from moldy job descriptions and the ruination of a bad idea, professors who create and conduct workshops of learning with the ebullience of orchestra conductors and movie directors.

\section{Application of the Theory:}

Utilization of technology offers real-time learning opportunities for students. Technology provides many new mechanisms for collecting, manipulating, and aggregating data. Large on-line data repositories provide for totally new kinds of learning experiences. Educators now have access to data providers, which supply browser-friendly interfaces such as thematic subject indexes and hierarchical search capabilities. Cross-discipline lexicons enhance the discovery process and provide reliable high quality datasets (DLESE, 2005). This combination and flexibility affords teachers and students opportunities to use real-time data, historical data, or import their own data for visualization, manipulation, or statistical analysis. In addition, "users are able to merge data sets, zoom in on a particular data set, and even combine a wide variety of datasets through data fusion enabled tools" (2005).

\section{Learning Technique Number 2 -Problem Based Learning}

Duch (1998) comments that the mainstay of traditional teaching is the lecture / listen ritual. Problem based learning, also known as problem solving learning, is as well an old fashion alternative that helps students develop critical skills needed today such as the ability:

"Proceedings of the 2005 American Society for Engineering Education Annual Conference \& Exposition Copyright 2005, American Society for Engineering Education” 
- to think critically, analyze and solve complex, real world problems;

- to find, evaluate, and use appropriate learning resources;

- to work cooperatively in teams and small groups;

- to demonstrate effective verbal and written communication skills;

- and to use content knowledge and intellectual skills to become continual learners.

According to Boud \& Feletti (1991), problem-solving learning is older than formal education itself, namely that learning is initiated by a posed problem, query, or puzzle that the learner wants to solve. In problem solving learning, complex, real problems motivate students to identify and research concepts and principles they need to know in order to progress through the problems. Students work independently or in small learning teams as they acquire and integrating information in a process that resembles that of inquiry.

Problem-solving learning has its roots in the medical school setting where small groups of mature, motivated students work to solve very real-world problems. In this process, problems are defined and researched, and high levels of learning occur as they progress through the exploration, analysis and implementation cycle.

Students soon see that learning is an ongoing process and that there will always be (even for the teacher) new learning issues to be explored. Because they learn concepts in context, they are more likely to retain that knowledge and apply it appropriately (Albanese \& Mitchell, 1993) in novel situations. As they work through real problems, students will be confronted with the realization that knowledge transcends artificial boundaries.

\section{Application of the Theory:}

Problem solving learning through context application is used extensively in courses involving programmable logic controllers. These devices use ladder logic programming involving dozens of instruction sets and function blocks. Students learn the basic attributes of each instruction set and function block, and are then supplied a "machine operating specification". The operating specification details the machine's sequence of operation and identifies requirements such as closed-loop feedback, continuous operation, starting, emergency stopping, and resetting to "home" position.

Now students must solve the problem (operating specification) armed with the software tools of instruction sets and function blocks. Once they think they have satisfied the operating specifications, they download their program to the controller and wire in discrete input and output devices. If the system operates in accordance to the specifications, their problem solving effort has succeeded. If not, they note ambiguities and develop a new set of software instructions. By repeating this design/test/revise process, students develop an analytical thought regime that parallels the traditional "scientific problem solving process".

"Proceedings of the 2005 American Society for Engineering Education Annual Conference \& Exposition Copyright 2005, American Society for Engineering Education" 


\section{Learning Technique Number 3 -Facilitating Group Learning}

Michaelsen (1998) feels that small group-based instructional methods can produce a wide variety of positive educational outcomes. These outcomes, however, only occur when instructors create conditions, which motivate students to prepare for and engage in giveand-take discussions.

Fortunately, by applying three fundamental principles, instructors can create these conditions in the vast majority of learning groups. These principles, referred to as "KEYS" in his essay, are: a) promoting individual and group accountability; b) using assignments that link and mutually reinforce individual work, group work, and total class discussions; and c) adopting practices that stimulate give-and-take interaction within and between groups.

\section{Application of the Theory:}

This type of interaction can be facilitated by dividing students into small groups of five or six and assigning chapters within the text. These teams of students are then divided into expert groups one through five. After each individual reads the text information all the ones from across all the groups gather for discussion of the material. During these groups students must become the expert of that information. When all major concepts have been addressed and worked through, the student returns to their original group and teaches the information they have acquired. Likewise, all of the other team members complete the same process; all of the twos meet, all of the threes and so on. The original team after teaching and learning all of the text components from each of the expert groups are tested individually on the material. This facilitation of group process provides a cooperative foundation for learning where every member is a teacher and a learner, while simultaneously placing the ownership for learning on each individual student.

\section{Learning Technique Number 4 - Changing Learning Behavior Outside the Classroom}

Gibbs (2000), in Changing Student Learning Behavior Outside Of Class suggests that teachers identify how many out of class "learning hours" they are entitled to and carefully plan how to make the most productive use of all of these hours. Teachers should establish explicit performance expectations to insure actual participation. Specifically, the use of formal assessment to capture learning time, thereby promoting enhanced learning.

\section{Learning Technique Number 5 - Preparing to Teach}

Doyle (2001) in Integrating Learning Strategies into Teaching suggests that we give thought to enhancing student learning, by asking and answering the following seven questions. 
Question \#1 - Prior Knowledge: What background information do my students need to be prepared for my course?

By letting students know what prior knowledge you are assuming they already have and by suggesting ways to review or fill in missing knowledge, you are increasing the likelihood for learning. In addition, by assessing students' prior knowledge with a background questionnaire, a pre-test, or other method (Angelo \& Cross 19993), you are taking a learner centered approach to your teaching (National Research Council, 1999). If you know what they know, you are much better able to connect the course content to their prior knowledge.

Question \#2 - Levels of Thinking: What cognitive level do my students need to operate at in order to be successful in my course? This question invites the instructor to think about the levels of thinking students need to learn the course material. If much of the course is just factual learning, then students will probably need little assistance. If, however,

students will be required to apply, evaluate, or synthesize information, then teaching them ways to do this may be vital to their learning success.

Question \#3 - Thinking Skills: What types of thinking skills and strategies do my students need to use to be successful in my course? If an instructor expects students to be able to summarize, use mind maps, or use a specific problem solving system, these may all need to be taught.

Question \#4 - Research Skills: What information gathering skills do my students need to be successful in my course? It is not safe to assume all students know how to use search engines or databases. Direct instruction in these areas will help ensure student success.

Question \#5 - Repair Strategies: What types of fix-up strategies do my students need to be successful in my course? Fix-up strategies are learning behaviors that help students to know what to do when they do not understand something.

If the course content is difficult and presents many situations where students may get lost or not understand, it may be necessary to teach them the steps to take, the questions to ask, and the resources to use that can lead to understanding. This situation is common in math, the sciences, and other numbers-based courses such as economics and statistics.

Question \#6 - Study Skills: What study skills do my students need to be successful in my course? Will they need to organize large amounts of information, summarize information, use rote memory techniques, or prepare for essay exams? Assisting students in developing study strategies which fit the type of testing (or other forms of assessment) used in the course and which reflect the amount and nature of the information that must be learned will go a long way to promoting academic success.

"Proceedings of the 2005 American Society for Engineering Education Annual Conference \& Exposition Copyright 2005, American Society for Engineering Education” 
Question \#7 - Learning Strategies: What types of learning strategies do my students need? Will they need to collaborate with others in small or large groups? Will students need to listen, maintain their attention for long periods of time, or take extensive notes? Students often need to be shown how to learn in class, how to work effectively in a group, how to engage in a discussion or debate, how to take notes, or even how to ask questions. Do not simply assume students know how to learn in your class.

Doyle concludes that after asking these seven questions, you will find yourself much better prepared to focus on the important strategies that can really aid student learning.

This second section focuses on teaching ideas and techniques. Topics included are: 1) The Seven "Good Practices" for Teachers; 2) Teaching with Hospitality; 3) The Importance of Listening; and 4) Assessment Via the Minute Paper. Specific applications of the theory are included in many of the teaching strategies.

\section{Teaching Technique Number 1 - Seven “Good Practices" for Teachers}

The following is a brief summary of the Seven Principles for Good Practice in Undergraduate Education as compiled in a study supported by the American Association of Higher Education, the Education Commission of States, and The Johnson Foundation. These Seven Principles are also presented in Arthur W. Chickering and Zelda F. Gamson's book entitled Applying the Seven Principles for Good Practice in Undergraduate Education (1991).

\section{Encourage Student / Faculty Contact}

Frequent student-faculty contact in and out of classes is the most important factor in student motivation and involvement. Faculty concern helps students get through rough times and keep on working. Knowing a few faculty members well enhances students' intellectual commitment and encourages them to think about their own values and future plans.

- I make a point to talk with my students on a personal level and learn about their educational and career goals.

- I seek out my students who seem to be having problems with the course or miss class frequently.

- I advise my students about career opportunities in their major field.

- I share my past experiences, attitudes, and values with students.

\section{Encourage Cooperation Among Students}

Learning is enhanced when it is more like a team effort than a solo race. Good learning, like good work, is collaborative and social, not competitive and isolated. Working with others often increases involvement in learning. Sharing one's own ideas and responding to other's reactions improves thinking and deepens understanding. 
- I have students participate in activities that encourage them to get to know each other.

- I use collaborative teaching and learning techniques.

- I encourage students to participate in groups when preparing for exams and working on assignments.

- I encourage students from different races and cultures to share their viewpoints on topics discussed in class.

\section{Encourage Active Learning}

Learning is not a spectator sport. Students do not learn much just sitting in classes listening to teachers, memorizing pre-packaged assignments and spitting out answers. They must talk about what they are learning, write about it, relate it to past experiences, and apply it to their daily lives. They must make what they learn a part of themselves.

- I ask students to present their work to the class.

- I ask my students to relate outside events or activities to the subjects covered in my courses.

- I give my students concrete, real-life situations to analyze.

\section{Give Prompt Feedback}

Knowing what you know and don't know focuses learning. Students need appropriate feedback on performance to benefit from courses. In getting started, students need help in assessing existing knowledge and competence. In classes, students need frequent opportunities to perform and receive suggestions for improvement. At various points during classes, and at the end, students need chances to reflect on what they have learned, what they still need to know, and how to assess themselves.

- I give students immediate feedback on class activities.

- I return exams and papers within one week.

- I discuss the results of class assignments and exams with students and the class.

\section{Emphasize Time on Task}

Time plus energy equals learning. There is no substitute for time on task. Learning to use one's time well is critical for students and professionals alike. Students need help in learning effective time management. Allocating realistic amounts of time means effective learning for students and effective teaching for faculty. How an institution defines time expectations for students, faculty and administrators, and other professional staff can establish the basis for high performance for all.

- I expect my students to complete their assignments promptly.

- I help students set challenging goals for their own learning.

- I explain to my students the consequences of non-attendance. 


\section{Communicate High Expectations}

Expect more and you will get it. High expectations are important for everyone-- for the poorly prepared, for those unwilling to exert themselves, and for the bright and well motivated. Expecting students to perform well becomes a self-fulfilling prophecy when teachers and institutions hold high expectations of themselves and make extra efforts.

- I encourage students to excel at the work they do.

- I give students positive reinforcement for doing exemplary work.

- I tell students that everyone works at different levels, and they should strive to put forth their best effort, regardless of what level that is.

- I revise my courses to challenge students and encourage high performance.

\section{Respect Diverse Talents and Ways of Learning}

There are many roads to learning. People bring different talents and styles of learning to college. Brilliant students in the seminar room may be all thumbs in the lab or art studio. Students rich in hands-on experience may not do so well in theory. Students need the opportunity to show their talents and learn in ways that work for them. Then they can be pushed to learning in new ways that do not come so easily.

- I encourage students to speak up when they do not understand.

- I use diverse teaching activities and techniques to address a broad range of students.

- I provide extra material or activities for students who lack essential background knowledge or skills.

\section{Teaching Technique Number 2 - Teaching with Hospitality}

According to Bennett (2001), we are fortunate that hospitality is practiced more than it is preached. A cardinal academic virtue, hospitality is essential in the classroom as well as in relationships with colleagues. In the context of engineering education, teaching with hospitality refers to the ability of the professor to provide a nurturing, conducive learning environment. This environment would include listening with respect, receptiveness to other opinions, and requiring the same level of interaction and courtesy from all students.

Although we seldom speak of hospitality as an academic virtue, many of us do practice it. We sense that it is more than a lingering piety, something inherited from the past whose point and purpose is now obscure. In fact, Bennet suggests that hospitality is a cardinal virtue and an essential requirement for what educators are all about.

Hospitality is essential to our calling because without genuine mutual sharing, the interactions that constitute educational activity become thin, impoverished transmissions of data, devoid of the excitement and the full personal impact that mark learning and its advancement. Without genuine openness to others, peer review is hobbled; and the 
conditions whereby knowledge can be validated, corrected, and expended are not in place. Without the mutual openness and reciprocity of sharing that are the marks of hospitality, the academy and the classroom become flat and impoverished - reverting to collections or conglomerates of individuals, not communities of learning.

The openness characteristic of hospitality can generate more satisfying teaching and learning. Faithfully practiced, hospitality yields more appreciation for the distinct gifts of the other, whether student or colleague; a greater comfort about the role and burden of being an authority; and more attention to the special responsibility educators have to others, a responsibility often captured by the concept of "trust" and best understood in terms of covenant, not contract.

\section{Teaching Technique Number 3 - The Importance of Listening}

According to Carbone (1999) in Listening in the Classroom: A Two-way Street, pure undistracted listening is one of the greatest gifts we can give each other as human beings. And refusing to listen can be one of the most damaging. No one can be forced to listen, but listening can be taught. It can be demonstrated through example, and it can be encouraged through the creation of a supportive environment. And listening to our students can be part of revitalizing our own teaching.

Carbone suggests that it is important to practice good attending behavior when listening to students as well. Give plenty of eye contact, nod and say "uh-huh" and resist any urges to glance at your watch. This communicates to each student that he or she is being listened to and creates a supportive environment.

Thought speed is estimated to be about 500 words per minute while speech speed is only about 125 words per minute. This means, roughly speaking, that we have about 400 words of extra thinking time during each listening minute (Nichols, 1987). The differential between thought speed and speech speed leaves a lot of time for the mind to wander, and once the mind has wandered it may be difficult to get back to listening. Encourage students to counteract this by using the extra thought time to mentally summarize the lecture material.

Listening, and processing what has been heard, takes time. Another way to encourage students to be good listeners is to allow them time to think about and process what they have just heard and to become curious about what is coming next. For example, even in large classes, the use of the one-minute paper can be an excellent thinking and processing break (Angelo \& Cross, 1993; Carbone, 1998; Harwood, 1996). Formulating a question about the material helps them to anticipate what may be coming next and to become curious about further exploration of the topic.

Listening to our students has benefits for us too. It can help keep us motivated and inspired and can enliven our teaching. By listening to our students, we can modify the

\footnotetext{
"Proceedings of the 2005 American Society for Engineering Education Annual Conference
} \& Exposition Copyright 2005, American Society for Engineering Education” 
examples and stories we use in lectures to match the cultural changes that take place over the years. This helps keep the material alive for both the teacher and the student.

Carbone concludes by pointing out that listening to our students creates a supportive environment in which students feel respected. If students feel respected and valued, they will be less afraid to ask questions, express opinions, and share insights; and they will be more likely to listen to each other during discussions. This is an environment conducive to the enhancement of learning.

\section{Teaching Technique Number 4 - Assessment Via the Minute Paper}

Angelo (2001) in Classroom Assessment: Guidelines for Success, identifies an excellent assessment technique called the "Minute Paper".

If you've ever wondered, as a class ended, how well your students really understood that day's material, then you understand the impetus behind classroom assessment. If you've ever been unhappily surprised by students' performance on a midterm, final, or major assignment, then you'll understand the need for classroom assessment. And if you'd like to benefit from lessons learned since 1986, by practitioners and researchers, on how to use classroom assessment to improve teaching and learning, then you may find this technique useful.

Researchers have long known that both students and teachers need clear, timely, and focused feedback to improve performance. Classroom Assessment Techniques (CATs) are simple methods faculty use to collect such feedback, early and often, on how well students are learning. Its purpose is to provide faculty and students with information and insights needed to improve teaching effectiveness and learning quality. Faculty use feedback gleaned through CATs to inform changes in their teaching.

The "Minute Paper" is one of the simplest, most widely used CATs, and a good example of the method. Attributed to Dr. Charles Schwartz, a physics professor at UC Berkeley, the Minute Paper has, been adapted and used since the mid-1980s in virtually every discipline. The Minute Paper asks students to respond anonymously to some variant of these two questions: (1) What are the 2-3 most important things you learned in class today? And (2) What questions remain uppermost in your mind? The "Muddiest Point", a variation on the Minute Paper developed by Professor Frederick Mosteller of Harvard, elicits useful feedback with just one question: "What was the muddiest point in today's lecture?" - or in today's discussion, lab, reading, quiz, or other learning activity.

By quickly scanning and summarizing responses to the CAT, the teacher can make welltargeted adjustments to the next class, recognize and capitalize on what students have learned well (or not learned), and clear up questions that might impede further learning. We've learned that Classroom Assessment is most effective when teachers: (1) explain why they are asking these questions, (2) share a summary of responses with students, and (3) discuss how they and the students can make best use of the feedback. Letting students 
in on the process helps promote active engagement, participation, and more reflective learning.

At first glance, faculty sometimes confuse CATs with the questions we ask in class, with tests and quizzes, or with familiar teaching techniques. Most teachers ask questions to check understanding. And most of us have noticed that typically only a small, not very representative percentage of students volunteer to answer. CATs, by contrast, elicit anonymous responses, usually in writing, from all or nearly all of the students.

Unlike quizzes and tests, CATs are for quickly assessing the whole group's learning, not for evaluating the work of individual students to assign grades. And while all faculty use teaching techniques, whether they know it or not, some faculty go a step further, using CATs to find out how well those techniques are promoting learning.

\section{Conclusion}

Educators must shift from a teaching centered environment to a learning centered paradigm. Learning can and should take place in a variety of venues facilitated by innovative methods of teaching. In Melsa's 2005 article "The "L" Word", a push for the real needs of learners is stressed. He states, "We need to stop worrying about "good" teaching and start worrying about how the learning experience for our students can be improved." As educators, we need to utilize the above-identified techniques and tips to ensure the very best learning experiences for our students.

\section{Bibliographic Information}

Albanese, M.A. \& Mitchell, S. (1993). Problem-Based Learning: A Review of Literature on Its Outcomes and Implementation Issues. Academic Medicine, 68. 52-81.

Angelo, T.A., (2001). Classroom Assessment: Guidelines for Success. In "Teaching Excellence". Center for Teaching, University of Southern Maine. Vol. 12, No 4, 2000-2001.

Bennett, J.B., (2001). Teaching With Hospitality. In "Teaching Excellence". Center for Teaching, University of Southern Maine. Vol. 12, No 1, 2000-2001.

Bound, D. \& Feletti, G. (1991). The Challenge of Problem-Based Learning (p. 13). New York: St. Martin's Press.

Chickering, A.W., and Gamson, Z.F. (1991). Applying the Seven Principles for Good Practice in Undergraduate Education. New Directions for Teaching and Learning. Number 47, Fall 1991. San Francisco: Jossey-Bass Inc.

Clarbone, E. (1999). Listening in the Classroom: A Two-Way Street. "Teaching Excellence". Center for Teaching, University of Southern Maine. Vol. 10, No 4, 1998-1999.

Doyle, T., (2001). Integrating Learning Strategies into Teaching. "Teaching Excellence”. Center for Teaching, University of Southern Maine. Vol. 12, No 6, 2000-2001.

"Proceedings of the 2005 American Society for Engineering Education Annual Conference \& Exposition Copyright 2005, American Society for Engineering Education” 
Dutch, B.J., and Allen, D.E., and White, H.B. (1998). Problem-based Learning: Preparing Students to Succeed in the $21^{\text {st }}$ Century. "Essays on Teaching Excellence". Center for Teaching, University of Southern Maine. Vol. 9, No 7, 1997 - 1998.

Gibbs, G., (2001). Changing Student Learning Behavior Outside of Class. "Teaching Excellence". Center for Teaching, University of Southern Maine. Vol. 11, No 1, 1999-2000.

Melsa, J. (2005). The "L" Word. Prism, American Society for Engineering Educators, Vol. 14, No 6, Feb. 2005

Michaelsen, L., (1998). Three Keys to Using Learning Groups Effectively. "Essays on Teaching Excellence". Center for Teaching, University of Southern Maine. Vol. 9, No 5, 1998.

Spense, L. (2000). Maybe Teaching is a Bad Idea. On line: www.teachingexcellence.org downloaded October 12, 2000.

\section{Biographical Information}

JOHN MARSHALL received his Ph.D. from Texas A\&M University and is the Internship Coordinator for the University of Southern Maine's Department of Technology. His specialization is Industrial Power and Automation, focusing on active/intelligent materials and advanced control systems. Grants have enabled him to design and equip a state-of-the-art power and control problem solving learning environment.

JUNE MARSHALL received her doctorate from North Carolina State University and is Chair of the Department of Education at St. Joseph's College in Maine. Her specialization is learning strategies focusing specifically in cooperative leaning and character education. 